\title{
Pituitary Metastasis: Central Diabetes Insipidus unmasked by Corticosteroids - Case Series and Review of Literature
}

\author{
Shree Vidhya N1, Tan J.K², Raja Nurazni R.A², Masni M¹ \\ ${ }^{1}$ Endocrine Unit, Department of Medicine, Putrajaya Hospital \\ 2Oncology Department, Institute Kanser Negara, Putrajaya Malaysia
}

Copyright: This is an open-access article distributed under the terms of the Creative Commons Attribution License, which permits unrestricted use, distribution, and reproduction in any medium, provided the original author and source are credited (CC BY 4.0)

Key words: Pituitary metastasis, Central diabetes insipidus, Pan-hypopituitarism, Corticosteroids

\section{Background}

Metastasis to the pituitary gland is rare encounter and is more common amongst the elderly population with advanced malignancy. An estimated $1 \%$ of all pituitary tumour resections are metastatic. Primary sites that frequently metastasize include breast and lung carcinomas. In the recent decade, advancement in the field of oncology with multiple modalities of therapy has led to prolonged survival of patients with advanced stages of malignancy. Herein, we present three cases and review of literature of pituitary metastasis presenting as central diabetes insipidus (CDI) incidentally unmasked following administration of corticosteroids.

\section{Objective}

To establish the common clinical features, establish variations in clinical presentations and natural progression of disease in patients with pituitary metastasis.

\section{Methods}

Three cases of central diabetes insipidus unmasked by corticostetoroids in pituitary metastasis were presented. A total of 9 other cases with central diabetes insipidus as first clinical manifestation unmasked by corticosteroid published from 2007-2018 were reviewed. Pertinent references were searched using windows remote search model on PubMed. The key words "pituitary metastasis" and "diabetes insipidus" searched in all fields resulted in 161 articles, of which articles of cranial diabetes insipidus as initial presentation without the use of corticosteroids were excluded. Searching "central diabetes unmasked by steroids" retrieved 8 additional references. Searching "metastatic carcinoma of pituitary" retrieved 35 additional references. About 20 new references were identified from the bibliographies of the articles reviewed. Ultimately, we identified a total of 18 references relevant to this research from the search terms. All references were reviewed to retrieve relevant references for this study. Non-English articles were excluded.

\section{Results}

A compilation of 9 previously reported cases of central DI unmasked by corticosteroids from 2007 to 2017 along with the present 3 cases were performed (Table 1). There was equal gender prevalence with a mean age of 61 (range $56-80$ years old). More than $75 \%$ of the cases described here had previously been diagnosed with advanced malignancies of varying primary sites. The remaining $25 \%$ presented with varying symptoms of hypopituitarism as the harbinger to the discovery of the primary neoplasm. Amongst the literature review and cases presented, primary malignancies with pituitary metastasis included lung adenocarcinoma (33\%), breast carcinoma (25\%), nasopharyngeal carcinoma (16\%), renal cell carcinoma $(8 \%)$, hepatocellular carcinoma $(8 \%)$ and gastric adenocarcinoma $(8 \%)$. It is noteworthy that two of three present cases identified, were the result of directly infiltration of nasopharyngeal carcinoma to the pituitary gland. There is limited data documenting the prevalence of nasopharyngeal carcinoma with pituitary metastasis within the Asian population.

\section{Conclusion}

Central diabetes insipidus unmasked by corticosteroids is a less recognized, potentially lethal but fully reversible complication of pituitary metastasis. Symptoms or signs of central diabetes insipidus should be sought in all 
patient with advanced malignancies presenting with polyuria and hypernatremia. Prompt restoration of pituitary hormones is warranted in affected patients to

\section{Introduction}

Metastasis to the pituitary gland is a rare encounter representing less than $1 \%$ of all pituitary lesions. The first reported case of metastasis to the pituitary gland was identified and reported (in German) by Benjamin L. in 1857 discovered during an autopsy of a patient with disseminated melanoma $(1,5,17)$. The increased prevalence in detection of pituitary metastasis denotes advancement in oncology treatment and options. These pituitary metastasis in advanced malignancies are most typically identified in the elderly population with diffuse malignancy. The most common primary tumours with metastasis to the pituitary gland are breast, lung and gastrointestinal malignancies. Their scarcity and usually indolent course, as well as the lack of specific clinical and radiological features, impede their differentiation from other more common sellar area lesions, particularly when history of malignancy is absent. Advancement in the field of oncology within the last decade has progressed with enhanced imaging modalities, improved surgical techniques, radical radio- and chemo-therapeutics for the treatment for systemic malignancies. This has led to augmented diagnosis of pituitary metastasis from primary tumours. Despite that, pituitary metastasis remains a challenge for diagnosis and remains poorly recognised and under reported. These pituitary metastasis are often discovered incidentally presenting with central diabetes insipidus having become unmasked after initiation of corticosteroids.

We report 3 clinical cases of pituitary metastasis diagnosed after incidental presentation of central diabetes insipidus after corticosteroid administration. A review of 9 other reported cases from 2007-2017 along with the current three cases were reviewed to establish common clinical features and clinical course of pituitary metastasis.

\section{Case 1}

Madam L, 67 year old lady diagnosed three years ago with stage four lung adenocarcinoma with extensive metastases to liver and bone presented to our centre with history of poor oral intake, generalised lethargy and reduced urine output for the past three days. She was admitted and treated as community acquired pneumonia and lymphangitis carcinomatosis where she received a week's course of intravenous ceftriaxone and $4 \mathrm{mg}$ dexamethasone daily. Initial sodium and potassium on admission was $145 \mathrm{mmol} / \mathrm{L}$ and $4.3 \mathrm{mmol} / \mathrm{L}$. However, five days later she developed confusion and polyuria with urine-output up to $4 \mathrm{~L} /$ day. Initial computed tomography (CT) of the brain showed thickened enhancing pituitary stalk and posterior lobe of the pituitary gland. Magnetic allow timely restoration of hormonal balance and preventing endocrine emergencies.

resonance imaging (MRI) showed a lobulated lesion in the right side of the posterior pituitary measuring $0.7 \mathrm{x}$ $1.0 \times 0.4 \mathrm{~cm}$ and a well-defined lesion measuring $0.7 \times 0.8$ $\mathrm{x} 0.6 \mathrm{~cm}$ at the superior aspect of the pituitary infundibulum. Biochemical markers supported the diagnosis of central diabetes insipidus with serum $\mathrm{Na}$ $156 \mathrm{mmol} / \mathrm{L}$, serum Osmolarity $309 \mathrm{mmol} / \mathrm{L}$ and urine Osmolarity $145 \mathrm{mmol} / \mathrm{L}$. She was treated with subcutaneous desmopressin and intravenous fluids. Further tests demonstrated panhypopituitarism and oral desmopressin, thyroxine and hydrocortisone was initiated. Patient opted for palliative care succumbing to 3 months after admission.

\section{Case 2}

Madam S, 56 year old lady diagnosed with stage four nasopharyngeal carcinoma presented to us with symptomatic hyponatremia in March 2017 having undergone combined chemo-radiotherapy the previous year. She was dehydrated with sodium of $115 \mathrm{mmol} / \mathrm{L}$ and potassium $3.9 \mathrm{mmol} / \mathrm{L}$. She responded to hydration as sodium increased to $128 \mathrm{mmol} / \mathrm{L}$. However, a week later sodium levels dropped to $119 \mathrm{mmol} / \mathrm{L}$ despite hydration. CT brain revealed increasing size of primary tumour with intracranial extension involving cavernous sinus, pituitary fossa and left temporal and pontine infiltration. Other investigations support the diagnosis of syndrome of inappropriate antidiuretic hormone secretion and she responded to fluid restriction. In addition, she was diagnosed with hypocortisolism (9am: $26 \mathrm{nmol} / \mathrm{L}$ ) and commenced on oral hydrocortisone $10 \mathrm{mg}$ twice daily replacement. Repeat CT staging on revealed disease progression and a pituitary mass of $1.7 \mathrm{x}$ $1.4 \times 1.7 \mathrm{~cm}$. She was readmitted for chemotherapy but discharged without hydrocortisone in June 2017. In July 2017, she was admitted for her third cycle of chemotherapy with sodium of $123 \mathrm{mmol} / \mathrm{L}$, potassium $3.4 \mathrm{mmol} / \mathrm{L}$ and was restarted on oral hydrocortisone $25 \mathrm{mg}$ tds. Unfortunately, she developed thirst and polyuria the same day with increasing sodium trend. Laboratory investigations revealed low urine osmolarity and high serum osmolarity with increasing serum sodium levels supported the diagnosis of central diabetes insipidus and subcutaneous desmopressin was administered. Complete pituitary hormonal panels support pan-hypopituitarism. She was discharged with hydrocortisone, thyroxine replacement and oral desmopressin but readmitted in September 2017 as her condition deteriorated. $\mathrm{Ct}$ brain showed disease progression with enlarging pituitary metastasis. Patient opted for palliative care and succumbed within 1 month. 
Mr C, a 55 year gentleman was diagnosed with advanced nasopharyngeal carcinoma, undifferentiated type, NOS, TNM: T4 N1 M0, Stage: IVA. He had completed combined chemo-radiotherapy in December 2017. Reassessment CT done in June 2018 revealed residual tumour at left inferior orbital fissure, left optic canal and left pterygopalatine fossa with local infiltration into the left cavernous sinus, pituitary sella and right sphenoid sinus. He was subsequently planned for chemotherapy with Paclitaxel/Carboplatin by the oncologist. He was admitted with symptoms of feeling unwell, vomiting, hypotension and hypoglycaemia. Morning serum cortisol and thyroid function revealed hypopituitarism. He was initiated on oral hydrocortisone and thyroxine replacement and was discharge home. He presented 4 weeks later via emergency with symptoms of polyuria, with inability to compensate and with documented urine output of more than $200 \mathrm{mls}$ per hour. Investigations and water deprivation test confirmed the diagnosis of central diabetes insipidus with serum osmolarity of 291, serum sodium of 149 and urine osmolarity $164 \mathrm{mmol} / \mathrm{L}$. Further history revealed that the onset of polyuria was soon after initiation of steroids however patient was able to compensate with large volumes of fluid intake, up to $4 \mathrm{~L} /$ day. He was discharged home with oral desmopressin $0.1 \mathrm{mg}$ daily in combination with other pituitary hormone replacement. He is planned for palliative chemotherapy in view of inoperable advance malignancy.

\section{Discussion}

The pituitary gland is an uncommon location for metastatic disease, although neoplasms from almost every tissue have been reported to metastasise there. In approximately two third cases of advanced malignancies, the patients were known to have metastatic disease prior to the discovery of pituitary metastasis. On the contrary, a third of patients, pituitary symptoms were the harbinger to the discovery of the primary neoplasm. The most frequent sources of metastases are: breast carcinoma (53\% of pituitary metastatic lesions) and lung carcinoma $(19 \%)(1,5,17)$. Metastatic spread is more common to the pituitary posterior lobe. A review of 201 cases of pituitary metastases demonstrated that the posterior lobe was involved in $84.6 \%(\mathrm{n}=170)$, with isolated posterior and anterior lobe lesions seen in 50.8 and $15.4 \%$ of cases respectively $[2,3,5]$. Many explanations for this predilection have been proposed. The posterior lobe is perfused directly by the inferior hypophyseal arteries, while the anterior lobe is supplied by a portal system around the infundibulum from the superior hypophyseal arteries, thus direct haematogenous spread may be more likely to seed to the capillaries of the stalk and posterior lobe. A further contributing factor is the fact the posterior lobe has a larger contact area with adjacent dura, facilitating meningeal spread though the suprasellar cistern [5].

Central diabetes insipidus (DI) is relatively common in pituitary metastasis, present in 42.3\% (95\% CI 36.2-48.5) of patients at presentation in one pooled study $(\mathrm{n}=248)$ [5]. Moreover, in a patient with known metastatic disease, the development of DI and radiographic evidence of a pituitary mass is strongly suggestive of a pituitary metastasis. DI in the setting of metastasis may be associated with a thickened pituitary stalk in combination with absence of the normal high T1 signal intensity in the posterior lobe (27). The high incidence of DI in metastatic lesions is consistent with the similarly high incidence of posterior lobe involvement.

Our study described three cases of occult ADH deficiency masked by concurrent ACTH deficiency; only once glucocorticoid replacement therapy had been administered did the symptoms diabetes insipidus appear. This 'masking' phenomenon could be due to a multitude of factors, both from $\mathrm{ADH}$-dependent and $\mathrm{ADH}$-independent mechanisms, resulting in impaired renal-free water clearance. Recognition of this phenomenon in patients with adrenal deficiency and risk factors for developing CDI is important in early diagnosis and management of this phenomenon [6].

The reasons for this are complex. Firstly, cortisol induces resistance of the $\mathrm{V} 2$ receptor (or at a post-receptor level) to $\mathrm{ADH}$, thus in states of glucocorticoid deficiency, the effects of $\mathrm{ADH}$ are amplified [7]. Secondly, Corticotrophin Releasing Hormone (CRH) stimulates ACTH and ADH release, thus glucocorticoid deficiency upregulates $\mathrm{CRH}$ and thus $\mathrm{ADH}$ release [7,8 ]. Lastly, hypocortisolaemia results in renal sodium loss and volume depletion, potent stimulators for increased (but "appropriate") $\mathrm{ADH}$ release. As such, when glucocorticoid deficiency is ameliorated, these compensatory mechanisms fail, and DI ensues. The high rate of DI in our study relative to the literature may be partly explained by our assessment of $\mathrm{ADH}$ function both before and after glucocorticoid replacement. Half of our cases had DI on initial assessment, similar to the prevalence in other studies, however the prevalence in our cohort increased to $75 \%$ after correction of hypocortisolaemia. Thus assessment of $\mathrm{ADH}$ function both before and after glucocorticoid replacement appears to increase the sensitivity for diagnosis of DI in the setting of pituitary metastasis. Overall life expectancy in patients with sellar metastases is 6-22 months.

A compilation of 9 previously reported cases of central DI unmasked by corticosteroids from 2007 to 2017 along with the present 3 cases were performed (Table 1). There was equal gender prevalence with a mean age of 61 (range $56-80$ years old). More than $75 \%$ of the cases described here had previously been diagnosed with advanced malignancies of varying primary sites. The remaining $25 \%$ presented with varying symptoms of hypopituitarism as the harbinger to the discovery of the primary neoplasm. Amongst the literature review and cases presented, primary malignancies with pituitary metastasis included lung adenocarcinoma (33\%), breast carcinoma (25\%), nasopharyngeal carcinoma (16\%), renal cell carcinoma (8\%), hepatocellular carcinoma $(8 \%)$ and gastric adenocarcinoma $(8 \%)$. 
Previous studies have reported a high prevalence breast carcinoma and lung carcinoma, however the Asian population shows a significant predilection for pituitary metastasis of nasopharyngeal carcinoma. The prevalence of NPC combined with the progression of disease with direct infiltration of the pituitary gland accounts for the presentation. However, there are no comparable studies looking into the frequency of nasopharyngeal carcinoma with pituitary metastasis.

The common presenting features in the present case series included significant polyuria, polydipsia with some patients presenting with an acute confusional state with the inability to compensate after the initiation of corticosteroids for pan-hypopituitarism. Symptoms of central diabetes insipidus was masked by the relative ADH deficiency. Most cases of pituitary metastasis presenting with central diabetes insipidus as the primary clinical presentation have led to an early diagnosis of pituitary metastasis. The perplexity arises when symptoms are masked and when patients present with symptoms of hyponatremia. Often, these preliminary signs to the presence of pituitary metastasis are often overlooked as these pathognomic symptoms are rare.
Advancement in imaging modalities with interest in neuroimaging has led to precision diagnosis pituitary metastasis. Amongst the literature review and cases presented, initial imaging by CT scan required more comprehensive images requiring MRI. The clinical outcome limited by late presentation in combination with advanced systemic disease should not be a limitation for precision imaging. Oncology offers targeted stereotactic radiosurgery as an effective palliative approach for most patients with pituitary metastasis. ${ }^{(18)}$

\section{Conclusion}

Central diabetes insipidus unmasked by corticosteroids is a less recognized, potentially lethal but fully reversible complication of pituitary metastasis. Symptoms or signs of central diabetes insipidus should be sought in all patient with advanced malignancies presenting with polyuria and hypernatremia. Prompt restoration of pituitary hormones is warranted in affected patients to allow timely restoration of hormonal balance and preventing endocrine emergencies. 
Table 1. Brief summary of cases discussed from clinical patients and literature review identifying clinical presentations, investigations, diagnosis and clinical outcome.

No age Sex Diagnosis

CR1

$67 \quad F$

Diagnosis : lung adenocarcinoma with extensive
metastases to liver and bone

Clinical presentation : developed confusion and

polyuria 5 days after initiation of dexamethasone

Diagnosis : nasopharyngeal carcinoma stage I

with pituitary metastasis

Clinical presentation : Started on Hydrocortisone

of pan-hypopituitarism and developed polyuria

CR 3

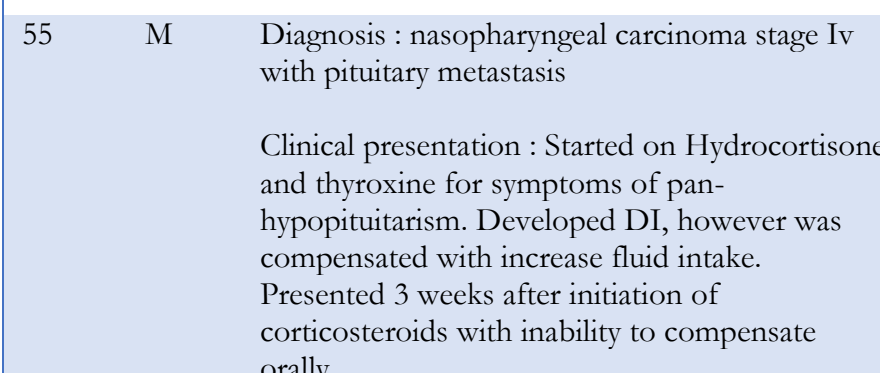
orally

Serum Urine $\quad \mathrm{Na} \quad$ Clinical outcome Imaging

osmo osmo $\mathrm{mmol} / \mathrm{L}$

$\mathrm{mmol} / \mathrm{L} \quad \mathrm{mmol} / \mathrm{L}$

\begin{tabular}{|c|c|c|c|}
\hline 309 & 115 & $\begin{array}{l}\text { Opted for palliative care } \\
\text { succumbing } 3 \text { months after } \\
\text { admission }\end{array}$ & $\begin{array}{l}\text { MRI showed a lobulated } \\
\text { lesion in the right side of } \\
\text { the posterior pituitary } \\
\text { measuring } 0.7 \times 1.0 \times \\
0.4 \mathrm{~cm} \text { and a well-defined } \\
\text { lesion measuring } 0.7 \times 0.8 \\
\times 0.6 \mathrm{~cm} \text { at the superior } \\
\text { aspect of the pituitary } \\
\text { infundibulum. }\end{array}$ \\
\hline & & $\begin{array}{l}\text { Patient opted for palliative } \\
\text { care and succumbed within } 1 \\
\text { month. }\end{array}$ & $\begin{array}{l}\text { CT brain revealed } \\
\text { increasing size of primary } \\
\text { tumour with intracranial } \\
\text { extension involving } \\
\text { cavernous sinus, pituitary } \\
\text { fossa and left temporal } \\
\text { and pontine infiltration. }\end{array}$ \\
\hline
\end{tabular}

$294 \quad 161 \quad 148 \quad$ For palliative chemotherapy with paclitaxel/Carboplatin
CECT Residual tumour at left inferior orbital fissure,

leftoptic canal with local infiltration into the cavernous sinus, pituitary sella and right sphenoid sinus 
Polyruric $>150$ cc urine output per hour

Diagnosis: Primary lung malignancy with cerebral and pituitary metastasis

diagnosed partial CDI initially obscured by

concomitant central hypocortisolism and possible

bronchogenic carcinoma-associated SIADH, only

becoming overt after steroid replacement.

Clinical Presentation: lethargy, poor oral intake,

functional decline and progressive confusion on a

background of visual blurring for a number of

months.

Low t4 $8 \mathrm{pmol} / \mathrm{L} \quad 8-21$

TSH $1.21 \mathrm{mIU} / \mathrm{L} \quad 0.34-5 / 60$

Am Cortisol $147 \mathrm{nmol} / \mathrm{L} \quad 240-618$

$\mathrm{LH}<1 \mathrm{IU} / \mathrm{L} \quad 11-59$

FSH 2 IU/L 17-11

Urine output $>2.7 \mathrm{~L} /$ day

\begin{tabular}{|c|c|c|c|}
\hline \multirow{10}{*}{$80 \quad \mathrm{~F}$} & \multicolumn{3}{|c|}{ hepatocellular carcinoma with pituitary metastasis } \\
\hline & GH & $0.360 \mathrm{ng} / \mathrm{mL}$ & $0.010-3.607 \mathrm{ng} / \mathrm{mL}$ \\
\hline & PRL & $6.83 \mathrm{ng} / \mathrm{mL}$ & $<12.3 \mathrm{ng} / \mathrm{mL}$ \\
\hline & TSH & $\begin{array}{l}1.288 \\
\mu \mathrm{IU} / \mathrm{mL}\end{array}$ & $\begin{array}{l}0.350-4.940 \\
\mu \mathrm{IU} / \mathrm{mL}\end{array}$ \\
\hline & FT3 & $1.78 \mathrm{pg} / \mathrm{mL}$ & $1.71-3.71 \mathrm{pg} / \mathrm{mL}$ \\
\hline & FT4 & $<0.40 \mathrm{ng} / \mathrm{dL}$ & $0.70-1.48 \mathrm{ng} / \mathrm{dL}$ \\
\hline & ACTH & $1.4 \mathrm{pg} / \mathrm{mL}$ & $7.2-63.3 \mathrm{pg} / \mathrm{mL}$ \\
\hline & Cortisol & $3.1 \mu \mathrm{g} / \mathrm{dL}$ & $4.0-19.3 \mu \mathrm{g} / \mathrm{dL}$ \\
\hline & Aldosterone & $10 \mathrm{pg} / \mathrm{mL}$ & $36-240 \mathrm{pg} / \mathrm{mL}$ \\
\hline & $\begin{array}{l}\text { Plasma } \\
\text { renin } \\
\text { activity }\end{array}$ & $0.5 \mathrm{ng} / \mathrm{mL}$ & $0.2-3.9 \mathrm{ng} / \mathrm{mL}$ \\
\hline
\end{tabular}

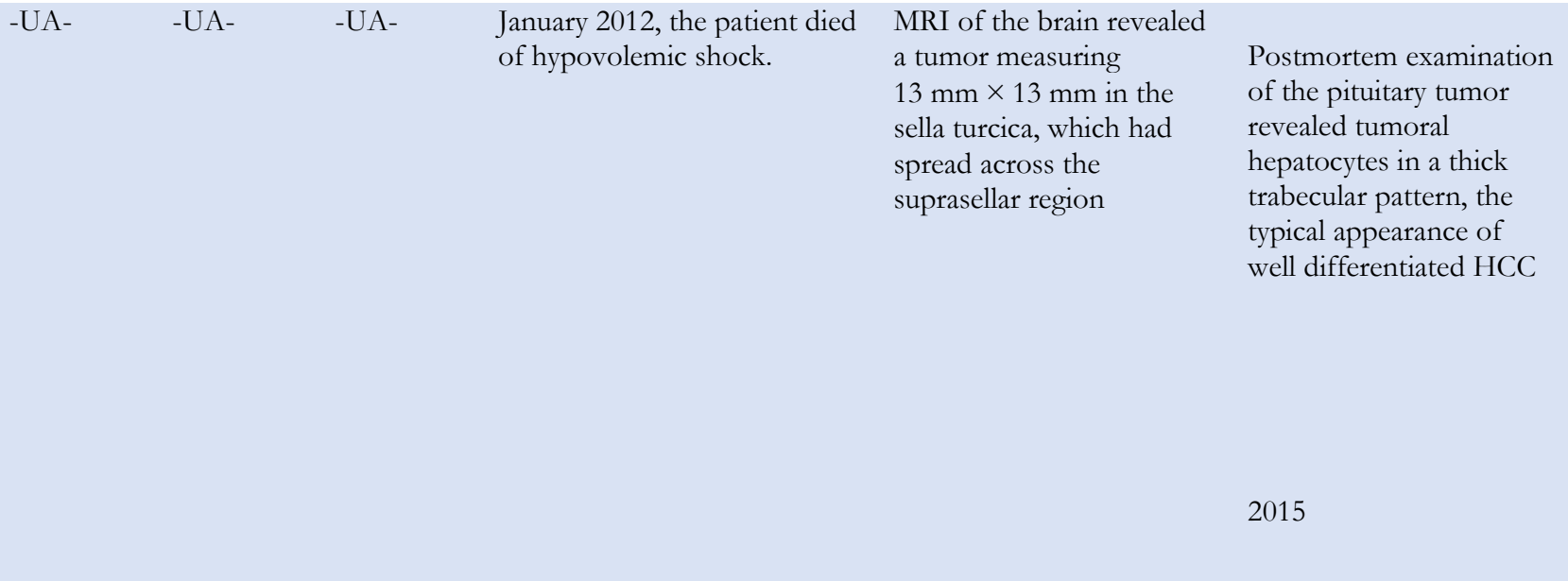

No biopsy due to advanced malignancy - palliative care with hypopit replacement

transferred to an inpatient hospice on nasal DDAVP and oral dexamethasone

$\mathrm{mm}$, and multiple

intracerebral

hypodensities with

perilesional oedema

consistent with

metastases
Indication for steroid- 1 For allergies cover for CT scan

2. dexa for perilesional

odema

March 2015 


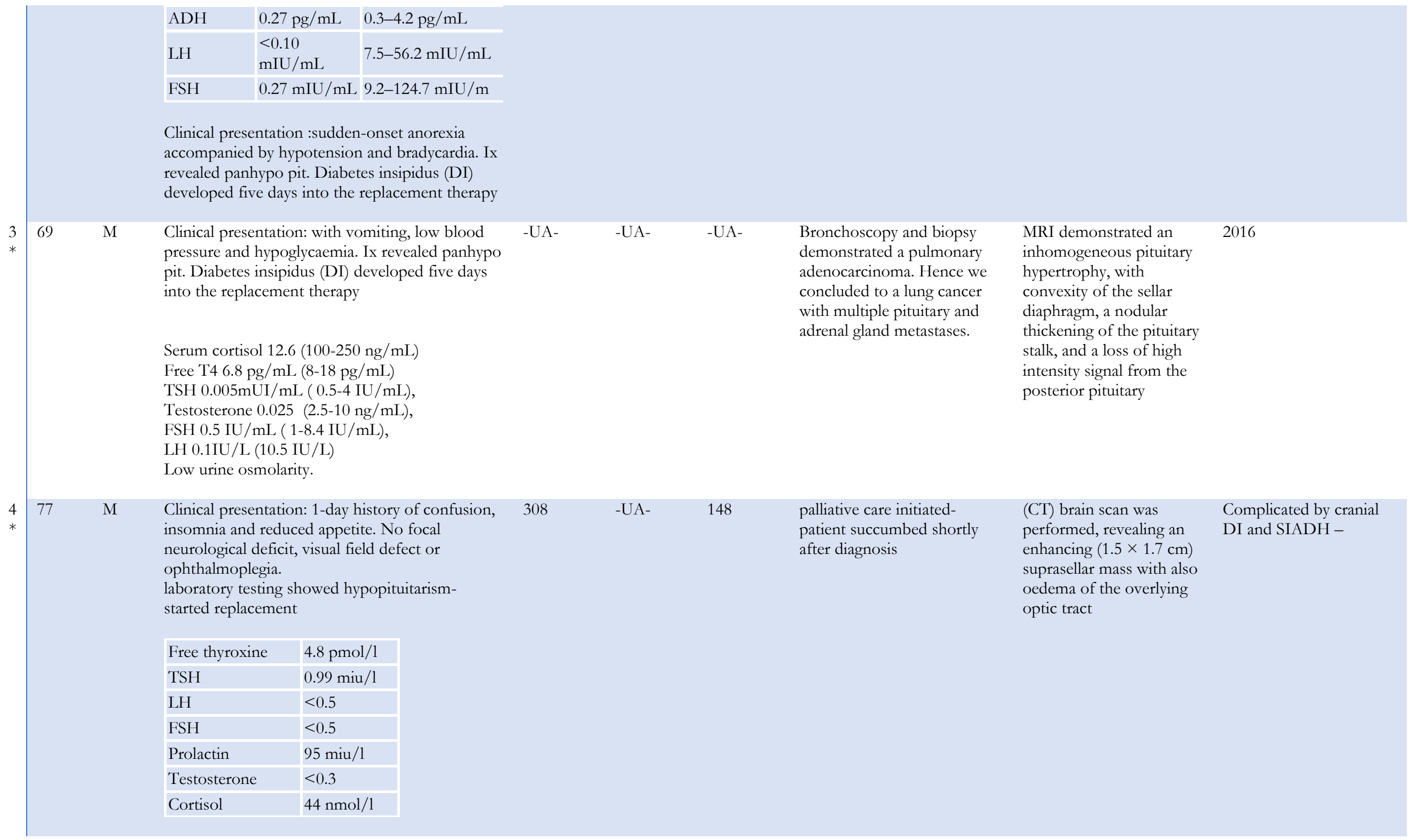




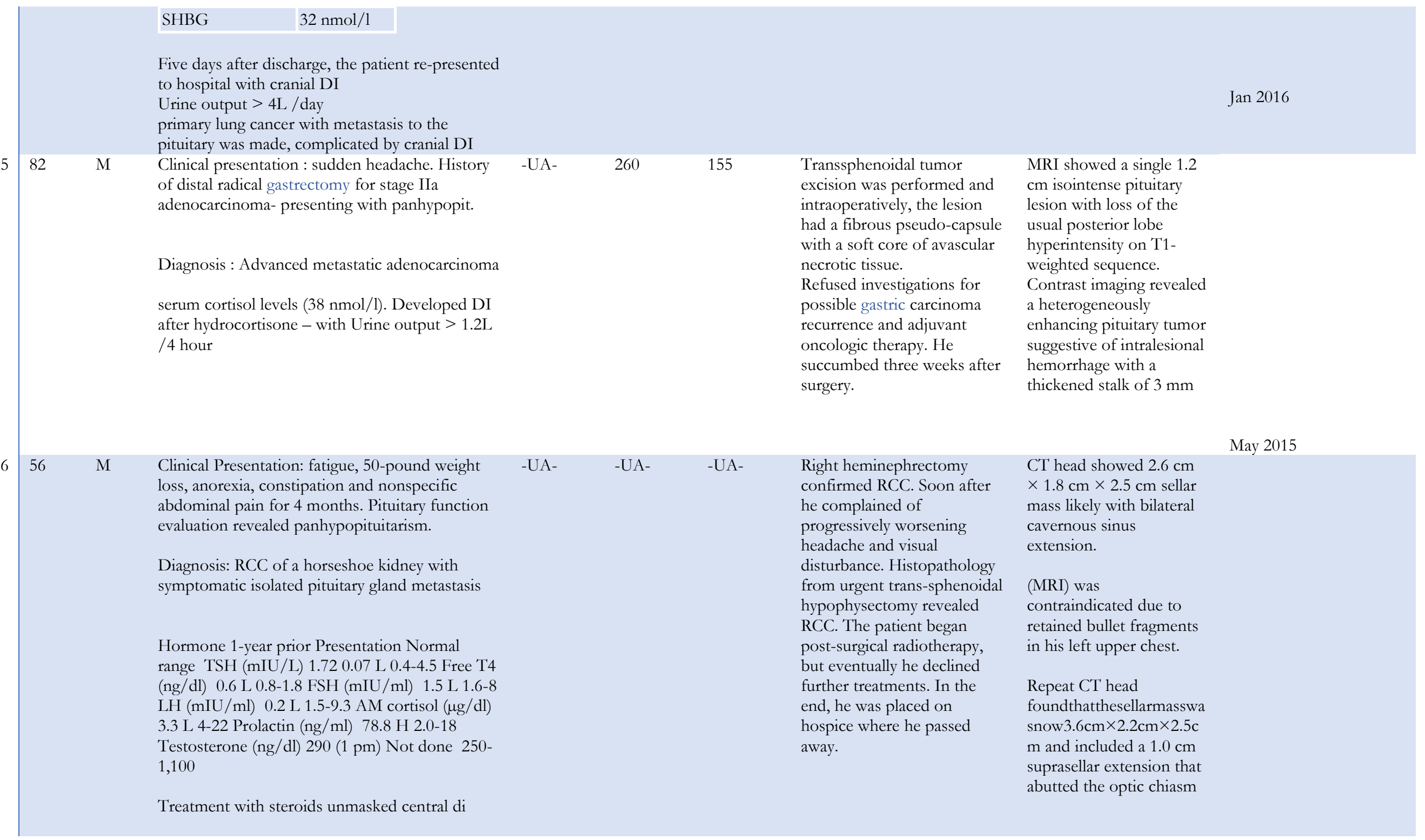


No documentation of clinical

requiring high ionotropic support. Initiated on

corticosteroids in ICU. Developed central DI 24

hours after steroid initiation

Diagnosis: Recurrent breast cancer with diffuse

bone and mediastinal metastases.

Further exploration of pituitary axis testing confirmed panhypopituitarism with a low FSH level in a postmenopausal patient and low serum levels of TSH, free T4, growth hormone, and IGF-1. Also, posterior lobe pituitary insufficiency was confirmed with levels of vasopressin and copeptin
Clinical Presentation : one month of weight loss and decreased appetite. She had no headaches, increased thirst or visual symptoms.

Diagnosis : Occult breast malignancy with extensive metastases.

Her biochemistries showed panhypopituitarism: ACTH 5.3 (010.2 pmol/L), cortisol $79 \mathrm{nmol} / \mathrm{L}$, Free Thyroxine $6(8-21 \mathrm{pmol} / \mathrm{L})$, Thyroid Stimulating Hormone $0.81(0.34-5.60 \mathrm{mIU} / \mathrm{L})$, Insulin-like GF 142 (81-225 ug/L), Prolactin 274 (73-478 mIU/L), FSH 3 (17-114 IU/L), Luteinizing Hormone < $1(11-59 \mathrm{IU} / \mathrm{L})$

4

312

$\begin{array}{ll}133 & 144 \\ & \text { Urine } \mathrm{Na} \\ & : 37\end{array}$

She was commenced on chemotherapy and brain radiation therapy.

Unfortunately, four weeks later, she passed away from cecal perforation and peritonitis. gait disturbance. His serum sodium level was

$117 \mathrm{mEq} / \mathrm{L}$. MRI revealed pituitary metastasis
Pituitary MRI showed

signal increase suggesting

hemorrhage in sagittal T1-

weighted and coronal T2-

weighted MRI, but

coronal T1-weighted MRI

with contrast showed

inhomogeneous

enhancement of pituitary

with metastasis.
Nov 2017

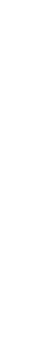

CT of the body and brain showed a mass in the cecum, suprasellar, and extensive intramuscular, bone, lung, lymph nodes and cerebellar deposits.

MRI of the pituitary fossa showed a $1.3 \times 0.9 \mathrm{~cm}$ suprasellar mass inseparable from the pituitary stalk. The pituitary gland was normal

\section{Magnetic resonance} imaging revealed a suprasellar tumor that showed inhomogeneous enhancement and was 
Diagnosis : Pituitary metastasis in a patient with

male breast cancer that resulted in pituitary

dysfunction from estrogen receptor-

positive breast cancer.

The patient underwent

conventional post-operative

radiotherapy combined with

hormone replacement

therapy and has remained

free of symptoms for 16

months. attached to the optic

chiasm.

July 2014 
1. Branch CL, Jr, Laws ER., Jr Metastatic tumors of the sella turcica masquerading as primary pituitary tumors. J Clin Endocrinol Metab. 1987;65:469-474. [PubMed]

2. He W, Chen F, Dalm B et al (2015) Metastatic involvement of the pituitary gland: a systematic review with pooled individual patient data analysis. Pituitary 18:159-168. https ://doi. org/10.1007/s1110 2-014-0552-2

3. Ref Komninos J, Vlassopoulou V, Protopapa D, Korfias S, Kontogeorgos G, Sakas DE, Thalassinos NC. Tumors metastatic to the pituitary gland: case report and literature review. J Clin Endocrinol Metab. 2004;89:574-80. doi: 10.1210/jc.2003-030395. [PubMed] [Cross Ref]

4. Delarue J, Chomette G, Pinaudeau Y, Brocheriou C, Auriol M (1964) Pituitary metastases. Frequency. Histopathologic study. Arch Anat Pathol (Paris) 12:179-182

5. Twelve cases of pituitary metastasis:A case series and review of the literatureMendel Castle-Kirszbaum Tony Goldschlager Benjamin Ho Yi Yuen Wang James King3 Springer Science+Business Media, LLC, part of Springer Nature 2018

6. Neurosarcoidosis-associated central diabetes insipidus masked by adrenal insufficiency Lemuel Non1, Daniel Brito1, Catherine Anastasopoulou2 BMJ Case Rep. 2015; 2015: bcr2014206390. Published online 2015 Jan 22. doi: 10.1136/bcr-2014-206390 PMCID: PMC4307084 PMID: 25612752

7. Ishikawa SE, Fukagawa A, Higashiyama M et al (2001) Close association of urinary excretion of aquaporin-2 with appropriate and inappropriate arginine vasopressin-dependent antidiuresis in hyponatremia in elderly subjects. $J$ Clin Endocrinol Metab 86:1665-1671. https ://doi.org/10.1210/jcem.86.4.7426

8. HX Chin, TPL Quek, MKS Leow, Central diabetes insipidus unmasked by corticosteroid therapy for cerebral metastases: beware the case with pituitary involvement and hypopituitarism. JOURNAL OF THE ROYAL COLLEGE OF PHYSICIANS OF EDINBURGH VOLUME 47 ISSUE 3 SEPTEMBER 2017247 -9 | doi: 10.4997/JRCPE.2017.307 Endocrine Society's 97th Annual Meeting and Expo, March 5-8, 2015 - San Diego

9. Pituitary metastasis of hepatocellular carcinoma presenting with panhypopituitarism: a case report Tomoko Tanaka, Katsushi Hiramatsu, Takuto Nosaka, Yasushi Saito, Tatsushi Naito, Kazuto Takahashi, Kazuya Ofuji, Hidetaka Matsuda, Masahiro Ohtani, Tomoyuki Nemoto, Hiroyuki Suto, Tatsuya Yamamoto, Hirohiko Ka, Yasunari Nakamoto BMC Cancer. 2015; 15: 863.Published online 2015 Nov 6. doi: 10.1186/s12885-015 1831-7

10. An acute adrenal insufficiency revealing pituitary metastases of lung cancer in an elderly patient Hela Marmouch,1,\& Sondes Arfa,1 Saoussen Cheikh Mohamed,2 Tensim Slim,1 and Ines Khochtali Pan Afr Med J. 2016; 23: 34. Published online 2016 Feb 8. doi: 10.11604/pamj.2016.23.34.8905

11. Competing interests in a lung cancer with metastasis to the pituitary gland: syndrome of inappropriate ADH secretion versus diabetes insipidus. Oxf Med Case Reports. 2016 Jan; 2016(6): 125-129. Published online 2016 Jun 1. doi: 10.1093/omcr/omw044 PMCID: PMC4887828 PMID: 27274855 Gaurav Singh Gulsin,1,* Madeleine Louisa Bryson Jacobs,2 Shailesh Gohil,3 Adam Thomas,4 and Miles Levy3

12. Symptomatic Metastasis to the Pituitary Gland: A Report of Three Cases and Review of the Literature. J Neurol Disord 3:236. doi: 10.4172/2329-6895.1000236 Yung C, Timothy SKC, Peter KHP, et al. (2015)

13. Isolated pituitary metastasis from renal cell carcinoma in a horseshoe kidney Kay KWin, Nissa Blocher, William Tester, Serge Ginzburg, Lauren Pomo Journal of Solid tumor DOI: https://doi.org/10.5430/jst.v8n1p37 2018

14. Acute-Onset Panhypopituitarism Nearly Missed by Initial Cosyntropin Testing. ClaudineA.Blum,1 DanielSchneeberger,1 MatthiasLang,1 JankoRakic,1,2 MarcPhilippeMichot,1 andBeatMüller1 1 Medical University Clinic ,Kantonsspital Aarau,Aarau,Switzerland 2 Department of Pneumology,MedicalClinic,KantonsspitalBaden,Baden,Switzerland Published 3 October 2017 Case Reports in Critical Care Volume 2017, Article ID 7931438, 4 pages https://doi.org/10.1155/2017/7931438

15. PITUITARY METASTASIS SECONDARY TO OCCULT BREAST MALIGNANCY: A CASE REPORT Kalpana Vijakumar, MBBS, Su Ping Brenda Lim, MBBS, MRCP, Wai Han Hoi, MBBS, MRCP Tan Tock Seng Hospital ABSTRACTS - Pituitary Disorders/Neuroendocrinology Jan 2016

16. A case of pituitary metastasis in a patient with male breast cancer developing anterior lobe dysfunction successfully treated by using hormone replacement therapy Fukunaga A1, Yazaki T, Shimizu K, Ochiai M. Department of Neurosurgery, Kyosai Tachikawa Hospital. No Shinkei Geka. 2014 Jul;42(7):629-33. PMID: 25006103

17. Benjamin. L.: Ein Krebs Fall. Virchows Arch. Path. Anat. 12 (857) 566-569

18. Stereotactic radiosurgery for pituitary metastases. Surg Neurol. 2009 Sep;72(3):248-55; discussion 255-6. doi: 10.1016/j.surneu.2008.06.003. Epub 2008 Sep 11 Kano H1, Niranjan A, Kondziolka D, Flickinger JC, Lunsford LD. 